\title{
O PROCESSO DE DESENVOLVIMENTO DO EROTISMO: MAX WEBER, NORBERT ELIAS E AS EMOÇÕES
}

\author{
Caio César Pedron (D)1
}

\section{Resumo}

O pensamento de Max Weber (1864-1920) e Norbert Elias (1897-1990) possuem uma série de afinidades que já foram exploradas por diversos trabalhos nas últimas décadas, como, por exemplo: a relação entre processo de racionalização e processo civilizador; a relevância da interpretação histórica em suas perspectivas; a busca pela objetividade e pela cientificidade e a relação entre a disciplina e o controle do comportamento humano como chave da mudança social. $O$ respectivo estudo se insere dentro deste debate maior e se distingue do que até agora foi produzido pela escolha do erotismo como objeto de observação e comparação na obra de ambos, creio que seria possível, por meio deste trabalho, salientar e ampliar a discussão ao entorno do esboço de desenvolvimento genético da erótica proposto por Max Weber e discutido enquanto desenvolvimento histórico - durante várias páginas do processo civilizador de Elias. Além disso, trataremos os dois constructos teóricos como socialmente situados, isto é, interpretaremos como expressões históricas que representam um discurso sociológico específico sobre o erotismo e a sexualidade.

Palavras-chave: Erotismo; Civilidade; Racionalização; Desenvolvimento.

\section{THE EROTIC DEVELOPMENT PROCESS: MAX WEBER, NORBERT ELIAS AND THE EMOTIONS}

\section{Abstract}

The thought of Max Weber (1864-1920) and Norbert Elias (1897-1990) has a chain of affinities that have been explored for different works in the last decades, such as, for example: the relationship between the rationalization process and the civilizing process; the relevance of historical interpretation to their perspectives; the search for objectivity and scientificity and the relationship between discipline and the control of human behavior as the major key of societal change. This study fits within this major debate and differs from what has been produce so far by the choice of eroticism as an object of observation and comparation in the work of both, I believe it would be possible, through this work, to show and expand the discussion around the sketch of genetic

\footnotetext{
${ }^{1}$ Doutorando em Sociologia pelo PPGS da Universidade Estadual de Campinas. Tem como objeto de estudo a teoria social clássica, com ênfase nas seguintes sociologias especiais: histórica, econômica, da religião e do amor. E-mail para contanto: caiopedron99@gmail.com.
} 
development of erotic proposed by Max Weber and discussed - as a historic development - during several pages of Elias civilizing process. In addition, we will deal with the two theoretical constructs as socially situated, we will interpret them as historical expressions that represent a specific sociological discourse on eroticism and sexuality.

Keywords: Eroticism; Civility; Rationalization; Development.

\section{Introdução}

Havia em primeiro lugar o círculo dos sociólogos. Uma das particularidades da Universidade de Heidelberg então era que a sociologia desfrutava ali um de um status elevado. A lembrança de Max Weber contribuía muito para isso. Alfred Weber não se contentava em gerir sua herança espiritual, mas a sua maneira dava novos impulsos a esse domínio científico. E a viúva de Max Weber, Marianne, desempenhava papel importante como legatária de uma tradição da qual falaremos adiante. Max Weber e sua obra certamente ainda não tinham a reputação internacional que adquiriram mais tarde. Mas para o status da sociologia na Alemanha, e evidentemente sobretudo para Heidelberg, a presença de um sociólogo exemplar, cuja irradiação ultrapassava de longe os limites de seu próprio domínio, era de importância capital (ELIAS, 2001a, p.103-104).

Esse pequeno excerto retirado da autobiografia de Norbert Elias (18971990) retrata o ambiente intelectual da Universidade de Heidelberg logo após o falecimento de Max Weber (1864-1920), pois entre 1925 e 1930 o ainda jovem Elias participou efetivamente da vida cultural da cidade universitária que era considerada a mais liberal da Alemanha (HONIGSHEIM, 2017, p.123) e vista como a "meca da sociologia" pelo próprio autor. O recém doutor - na época tinha 28 anos - migrou para a cidade em busca de uma indicação para privatdozent $^{1}$ e foi acolhido por Karl Mannheim que era um dos pupilos de Alfred Weber.

Nesse período foi aconselhado pelo mesmo Mannheim a frequentar as reuniões do círculo de Marianne Weber, dizia-se que a pensadora possuía forte influência sobre cunhado e que, por isso, frequentar as reuniões dominicais - os jours - era de fundamental importância para acelerar a sua nomeação. Não há registro no ensaio/memorial do grupo redigido por Marianne Weber (1977) da presença de Elias, contudo, podemos crer na veracidade do autor, tendo em

\footnotetext{
1 Haviam três categorias profissionais no professorado universitário alemão, privatdozent: instrutor privado "credenciado" pela universidade; ausserordentlicher Professor, Extraordinarius: professor contratado com salário mais baixos e muitas atribuições; ordentlicher Professor, Ordinarius: o professor catedrático que tinha a sua própria disciplina, seminários de pesquisa e um belo ordenado no final do mês. Elias trabalhava, em época, como uma espécie de instrutor privado não credenciado, assessorando Mannheim que já era privatdozent e trabalhando por conta própria.
} 
vista a proximidade com Mannheim que foi um visitante frequente no período e, também, que logo após a retomada das atividades - por volta de 1921-1922 muitos eram os jovens frequentadores das reuniões no solar. A sensação de pertencimento ao círculo do Weber Kreis fez o autor em suas memórias afirmar: "no salão da viúva de Max Weber eu não fora rejeitado (ELIAS, 2001, p.107).

Estes primeiros parágrafos nos servem de aproximação para compreendermos a relevância de Max Weber na formação ${ }^{1}$ sociológica de Norbert Elias ainda no período em que começava a dedicar-se aos estudos sociológicos - havia cursado alguns semestres em medicina e filosofia em 1918. Teve acesso, graças ao psicólogo e filósofo Karl Jaspers, ao opus magnum weberiano: Economia e Sociedade, obra que Elias tratou de chamar de "bíblia" para os sociólogos e, depois, participou das reuniões e da atmosfera heidelbergense. Partindo dessa premissa, é possível afirmar que o diálogo entre as teorias de Elias e Weber não só é possível como, também, adequado, pois ambos tratam dos processos históricos de transformação que constituíram para cada pesquisa - a singularidade ocidental e estavam imersos em uma atmosfera de produção de conhecimento sociológico bastante parecida. Essa tradição que combina ciências da cultura e história é fundamental como mediadora das proximidades entre ambos.

Um ponto ainda pouco salientado na comparação entre os dois autores é o papel que o amor tem para cada uma das teorias, já é sabido por muitos que na Consideração Intermediária Max Weber trata do desenvolvimento de uma esfera de valor autorreferente cujo principal fundamento está posto na intensificação do desejo erótico como possibilidade de experimentação de uma redenção intramundana ainda que: efêmera, individual e egoísta². Para Elias, trata-se de observar o comportamento entre os sexos para retirar deles indícios que sustentem a sua tese de que o processo civilizador avançou por sobre todas as condutas passionais que expressavam a violência, irracionalidade e a inconsciência; o autor acreditava que por meio de um processo de pacificação dos instintos foi-se emergindo um padrão de comportamentos adequados à vida civilizada.

\footnotetext{
${ }^{1}$ Não é de todo sem valor que o sobrenome Weber tenha 120 entradas em sua autobiografia. Como nos mostra Landini (2005): alguns autores afirmam que do mesmo modo que Weber haveria de ter um diálogo com o espírito de Marx, Elias teria com o espírito de Weber. Embora não seja especialista na sociologia de Elias, creio que o diálogo com Weber se dá mais pelo objeto de pesquisa escolhido e pela tradição sociológica - vemos um diálogo bastante intenso com Durkheim também - do que propriamente uma relação de conflitualidade imanente na teoria dos dois autores.

${ }^{2}$ Em suma: efêmera porque sempre provisória, durando o tempo da experiência sexual ou do romance passional; individual, porque não necessariamente compartilhável, as pessoas experimentam o amor e o sexo sempre da parte de si mesmas, mesmo que sintam aquela "comunhão experimentada como unificação completada"; egoísta, porque sempre parte de uma exploração do parceiro, do gozo sofisticado de si no outro (WEBER, 2016). Para uma abordagem mais ampla sobre o problema de se encarar a salvação intramundana como emancipatória, ver: PEDRON, C. C. Salvação intramundana pela perversão? Sobre a possibilidade emancipatória através da esfera erótica de Max Weber in: QUERIDO, F.M. (et al.). Teorias Críticas entre passado e presente, Coleção Ideias; IFCH, 2019.a.
} 
O objetivo desta pesquisa está dado no ato de contrapor as duas teorias em um ponto específico que é o do entendimento de que houve um desenvolvimento da erótica como processo histórico/genético, ou seja, como progressão - não unilateral - de comportamentos que intensificaram a importância social da sexualidade. Para tanto, percorreremos o seguinte trajeto: 1) em uma espécie de excurso, faremos uma apresentação rápida dos contrapontos entre os autores, pois sem isso não será possível entender os pontos de contato e distanciamento entre as obras de cada um; 2) após isso, será empreendida uma comparação entre a genealogia da erótica em Max Weber e a genealogia em Elias, destacando principalmente a transição entre Idade Média, Antigo Regime e Contemporaneidade, pois é nesse ponto que as duas teorias se cruzam; 3) por fim, na conclusão, faremos uma pequena digressão sobre como a interpretação de cada um desses autores moldava um certo ponto de vista sobre a sexualidade no período em que viviam.

\section{Uma consideração preliminar: os pontos de tensão entre Weber e Elias}

Antes de iniciarmos o movimento de aproximação de cada uma das construções teóricas urge situá-las - ainda que muito sumariamente ${ }^{1}$ - em suas diferenças, para que as comparações não sejam tomadas como entre identidades teóricas. Elias nunca escondeu que o seu principal incômodo para com a sociologia clássica - incluindo aí Weber - era dado pelos limites de suas dualidades, pois estas concebiam o homem como isolado de seus pares na sociedade ou a sociedade como um sistema externo às ações individuais. 0 problema do homo clausus, como salienta Landini (2005, p.16), é fundamental para a constituição do seu conceito basilar que é a (con)figuração, pois:

Ao contrário, o indivíduo só pode ser entendido em termos de sua vida em comum com os outros. A estrutura e a configuração do controle comportamental de um indivíduo dependem da estrutura das relações entre os indivíduos. A base de todos os malentendidos no tocante à relação entre indivíduo e sociedade reside no fato de que, embora a sociedade, as relações entre as pessoas, tenha uma estrutura e regularidade de tipo especial, que não podem ser compreendidas em termos do indivíduo isolado, ela não possui um corpo, uma "substância" externa aos indivíduos (ELIAS, 2015, p. 1065-1069).

os olhos de Elias, a sociologia de Weber - como exposta em Economia e Sociedade $^{2}$ - estava presa a tipologia da ação que, por sua vez, impedia qualquer tipo de superação do dualismo. Não importa muito se a opinião de Elias

1 Não pretendo desenvolver uma contraposição sistemática entre os dois autores, somente essa atividade renderia um ótimo artigo sobre métodos na sociologia histórica ou epistemologias, mas penso que seria contraproducente para o objetivo central que é o de mostrar as afinidades no tratamento da emergência histórica do erotismo.

2 Elias parece ter mais apreço pela sociologia empírico-histórica, aquela que está presente na coletânea de ensaios intitulada Ética Econômica das Religiões Mundiais. 
sobre a teoria weberiana estava certa ou não ${ }^{1}$, o que queremos afirmar é que o principal ponto de distanciamento dele para com Weber estava dado nos limites que o autor acreditava encontrar na teoria da ação social. Mas não parava por aí, Elias também questionava a ideia do processo de racionalização, justamente no período onde se confirmava a interpretação de sua relevância como unidade temática dos escritos weberianos (TENBRUCK, 1980), diz ele:

Talvez seja um tanto equivocado chamar esse recuo das explicações emotivas pela via da fantasia ou, para usar a fórmula emotiva de Max Weber, esse "desencantamento do mundo", de processo de racionalização. Como quer que o termo seja utilizado, ele sugere que o que mudou afinal foi a "razão" humana; parece implicar que as pessoas se tornaram mais "racionais" ou, em linguagem simples, mais sensatas que em tempos anteriores. É uma autovaloração que dificilmente faz jus aos fatos. Só se começa a entender a mudança referida pelo conceito de racionalização quando se reconhece que uma das mudanças por ele acarretadas é o aumento do conhecimento social orientado para os fatos, conhecimento capaz de conferir uma sensação de segurança (ELIAS, 2001, p. 49).

A dúvida que o advérbio talvez poderia provocar ao leitor desavisado é só uma forma de abrandar a dura crítica à ideia de um processo de racionalização nos termos weberianos. Ambos os processos - civilizador e de racionalização tratam de uma superação progressiva das irracionalidades que orientavam as ações e figurações dos homens só que, para Elias (1990) se tratava de refrear impulsos, controlar comportamentos e impingir na estrutura de personalidade dos indivíduos uma forma de autocontrole; enquanto que em Weber o processo de racionalização está vinculado à superação da magia - a "fórmula emotiva" do desencantamento do mundo - e à emancipação do homem frente à própria religião, defenestrada do seu pedestal pela ciência.

Talvez o ponto central da dissenção entre os dois processos seja a direção que cada um imprime ao desenvolvimento, pois Elias fala em segurança proporcionada pelo controle dos afetos - segurança física - enquanto Weber apresenta a insegurança existencial e crônica de se viver em um mundo onde a colisão dos valores ${ }^{2}$ impede qualquer superação posterior. O homem passa a ser fragmentado, tal qual o vilão do filme com suas múltiplas personas ${ }^{3}$, só que no lugar delas, se colocam os diferentes regramentos com validade circunstancial

1 Não importa para a nossa tese, obviamente que já se vem discutindo há décadas as contribuições dos clássicos para os problemas teóricos atuais, a ideia de que a sociologia de Weber é um análise micro/macro cujo ponto central está dado exatamente no problema da transformação ou a visão de um paradigma weberiano (SCHLUCHTER, 2008) assentado em múltiplos níveis são só alguns dos elementos que renovaram o pensamento do autor e lhe deram ainda mais destaque por sobre a antiga acusação de individualismo enclausurado.

2 A tese do politeísmo não é a "prova" de que Max Weber seja um relativista ético, muito pelo contrário, ela aponta para um absolutismo ético (SCHLUCHTER, 2011) muito mais rigoroso do que se poderia interpretar. Weber, definitivamente, era mais Kant do que Nietzsche.

3 Fragmentado. Direção de M. Night Shyamalan. EUA: Universal Pictures. 2017. 
que se interpõe à ação global. Esse é outro ponto que incomoda o pensamento eliasiano, pois este autor compreende a segmentação da sociedade em esferas, subsistemas ou campos como um limite dado que:

A industrialização, a cientifização, a burocratização, a urbanização, a democratização ou o crescimento do nacionalismo- seja qual for o conceito que se tome para demonstrar o paralelismo na mudança social, só realça um ou outro aspecto particular. Os nossos instrumentos conceptuais não estão suficientemente desenvolvidos para exprimir a natureza da transformação social global, nem para explicar as relações entre os seus aspectos individuais. $E$, no entanto, o problema sociológico que nos diz respeito está precisamente nisso. A direção comum tem que ser esclarecida, não só numa esfera, mas nas transformações mutuamente interligadas das relações humanas (ELIAS, 2008, p. 68).

Portanto, compreender a modernização como compartimentalização dos indivíduos em subsistemas sociais autônomos e segregados é percebê-la sob um viés ainda marcado por uma transliteração das ciências naturais para os problemas sociais atribuindo-Ihes uma forma "mecânica". Contra isso, o autor propõe a compreensão das esferas como "relações funcionais de pessoas interdependentes" (ELIAS, 2008, p.69), sendo que o verbo funcionar adquire um sentido mais relacional e dinâmico do que propriamente extático e repetitivo. 0 conceito de configuração permite essa interpretação mais dinâmica e expõe mais uma faceta da crítica de Elias tanto ao individualismo metodológico quanto ao estruturalismo.

Por fim, o asceta intramundano superou os diferentes deuses, demônios, espíritos e entidades - através de um processo de educação que controlava e refreava qualquer emocionalismo - só para ficar refém dos valores que foram decantados em cada uma das esferas seculares. Portanto, a pretensa emotividade que o desencantamento ou mesmo o termo jardim encantado encerram, é, na verdade, um horizonte muito mais lúgubre do que a positiva convicção ${ }^{1}$ na ênfase da segurança proporcionada pelo processo civilizador. É possível afirmar que, para Elias, a racionalização faz parte do processo civilizador, mas não pode ser considerada o processo "mesmo" como bem lembrou Previatti (2016); enquanto que, para Weber, o processo civilizador pelo menos no que tange ao controle das emoções - e que é compreendido pela racionalização.

Poderíamos desenvolver inúmeras outras tensões entre o pensamento eliasiano e o weberiano no campo da teoria, bem como da epistemologia, por exemplo, na concepção do hiatus irrationalis que cinde a possibilidade de "contato" entre o sujeito e o objeto e que desemboca no choque entre os tipos

1Irônico que Elias seja acossado pela mesma vontade de julgar a ideia do processo de racionalização como autovalorização, justamente ele que foi acusado do mesmo mal quando, em seu processo civilizador, percebia um recrudescimento da violência e dos afetos mais passionais, isto exatamente durante a emergência da violência total do III Reich. 
ideais de Weber ${ }^{1}$ e os correlatos tipos reais de Elias (2001, p.39) ou até no papel secundário da religião no processo civilizador enquanto que, para o de racionalização, ela é determinante (embora não exclusiva). Contudo, creio que basta o que aqui foi exposto tendo em vista que o objetivo deste texto não é compará-los enquanto objetos, mas perceber as relações das suas teorias para com a erótica. Nas próximas páginas desenvolveremos a aproximação seguindo um ponto de vista determinante: investigaremos o desenvolvimento processual do erotismo na tipologia de Weber e, também, na interpretação de Elias; queremos, com isso, salientar os pontos de contato e as diferenças na interpretação que os dois fazem desta transformação.

\section{O desenvolvimento histórico do erotismo em Weber e Elias}

Podemos, agora, dedicarmo-nos ao que é fundamental na tipologia da erótica weberiana e na leitura que Elias faz do mesmo processo. A erótica weberiana é um texto composto em "duas partes", na primeira se apresenta uma tipologia genética de desenvolvimento - bastante simplificada - através da qual Weber expõe nas diferentes "épocas" do ocidente quais foram os principais influxos no desenvolvimento ou contenção da erótica; na segunda parte, o autor se impõe a tarefa de compreender o que é essa paixão sublimada em um afeto muito particular e quais as principais fonte de tensão entre a ética da fraternidade $^{2}$ e essa esfera. Comecemos tratando das etapas do desenvolvimento erótico ${ }^{3}$, elas seguem respectivamente o seguinte curso:

1) Grécia pré-clássica: nesse período a posse e o rapto de mulheres se equivalia à luta por tesouros e às batalhas por conquistas de poder (WEBER, 2016, p.389). A mulher era tratada como qualquer outro objeto e não tinha parte na relação erótica. A intensificação do desejo

\footnotetext{
1 Alguns autores, como Francisco Gil-Villegas Montiel, erram feio ao acreditar que, ao menos metodologicamente, Elias concordaria com o tipo ideal. Partindo da aceitação de Elias do asceta vocacional (2001.c.) o autor acredita que haveria por parte deste uma construção de outro tipo ideal, o ethos econômico aristocrático cortesão, como podemos perceber na seguinte frase: "El estudio de Norbert Elias busca así complementar las investigaciones de Max Weber y Karl Mannheim mediante un recurso legítimo y estimulado por ambos, o sea, la construcción de nuevos tipos ideales, en este caso el del ethos económico aristocrático" (MONTIEL, 2015, ps.12261-12264). Talvez, nesse tópico, Elias esteja mais próximo de Sombart (1958) que de Weber, embora seja necessário fazer justiça ao interprete, de fato o pensamento eliasiano compreende muito bem a pluralidade da ideia de racionalidade em Weber.

2 É interessante que o autor usa o tipo ideal de ética da fraternidade que conjugaria todas as religiões ocidentais, quando sabemos pelo próprio texto que existem limites em se chamar 0 protestantismo ascético de fraterno. Creio que esse é um dos problemas que Weber não resolveu muito bem em seu modelo da erótica, pois ainda que tenha apresentado algumas diferenças entre a resposta de Santo Agostinho, Thomas de Aquino, Lutero, Calvino e até William Penn, falta uma formação conceitual precisa do que seria (e de como enfrentaria a erótica) essa ética de (não-)fraternidade puritana, a fraternidade de seitas como os Quakers ou anabatistas e a ética da fraternidade, que me parece a "original", do catolicismo.

3 Trataremos mais especificadamente do segundo tópico na conclusão deste trabalho, colocando em diálogo o diagnóstico das condições do erotismo moderno em Weber e no pensamento de Elias.
} 
era eminentemente heterossexual, ainda que bastante primitiva em sua brutalidade.

2) Grécia Clássica: nesse período ocorrem fortes mudanças na direção e intensificação do desejo erótico. O objeto de desejo sexual passa a ser o companheiro mais jovem, o eromenos, tendo em vista que o rapto de mulheres deixa de ser necessário, sendo o casamento uma consequência natural e, portanto, pouco estimulante das relações amorosas. A atividade principal deste período é a pederastia, ou seja, o vínculo entre um jovem iniciando sua formação - em plena puberdade e somente enquanto não lhe nasciam os pelos - e um preceptor da vida adulta. Ocorre, então, uma masculinização das relações eróticas e uma direção da intensificação ligada à homossexualidade.

3) Idade Média: com a emergência do cristianismo e suas proibições sexuais, surge a primeira progressão na intensificação do desejo heterossexual. É possível perceber através do trovadorismo que aparece uma nova categoria de sujeitos do desejo, não mais a mulher como objeto, mas sim como personalidade que participa do "jogo de sedução". A dama é uma figura de transição fundamental, um mediador evanescente ${ }^{1}$ que transforma o relacionamento erótico entre homem e mulher em uma certa direção. A ação dessa personagem é o julgamento pelo olhar, pois através dessa avaliação subjetiva ela escolhe o vassalo que lhe aprouver.

4 ) Idade Moderna: no Renascimento o que ocorre é um desvio da direção erótica com um retorno a masculinização, a ênfase no duelo e na relação mais bruta faz com que os desejos sejam direcionados novamente para o camarada; não mais aquele efebo ateniense, mas, agora, o companheiro de armas. Aqui se apresenta um dos grandes limites do pensamento weberiano: a masculinização é quase que um sinônimo de brutalização e desvio do desenvolvimento requintado ${ }^{2}$ intelectualização do sexo - ou mesmo do seu caráter místico, como expressão extracotidiana do amor.

1 Concordo plenamente com a leitura de Fredrick Jameson (1973) de que as tipologias de Weber podem ser interpretadas através de instrumentos oriundos da análise narratológica. A dama, por exemplo, é retirada da literatura trovadoresca, por isso, já podemos considerá-la objeto narrativo. Sua função discursiva é a mesma que a de outros personagens, ser um mediador evanescente - na bonita tradução de Gabriel Cohn - que provoca uma determinada transformação social só para desvanecer no momento seguinte.

2 Não é muito diferente do que acontece com outros autores, a ideia de cultura feminina e até mesmo o coquetismo de Simmel também colocam essa ênfase da sofisticação da sexualidade como resultado da intensificação do valor da mulher nas relações eróticas e do erotismo enquanto subsistema social. O próprio Elias, como veremos a seguir, também estabelece esse vínculo entre brutalização e masculinização, o que demonstra os limites do pensamento dos primeiros sociólogos sobre as mulheres e sobre o homoerotismo. Um ótimo contraponto, no que tange as mulheres nos é oferecido pelo pensamento de Marianne Weber, ver: WEBER, Marianne. Excerpt from "Authority and Autonomy in Marriage. In: Lengermann, Patricia Madoo; Niebrugge, Gillian. The Women Founders: Sociology and Social Theory 1830-1930 . New York: Waveland Press.1998. Edição do Kindle. 
5) Cultura dos Salões: neste período se dá o salto definitivo, retomando à intensificação heterossexual, em direção à erótica enquanto expressão intelectualizada das paixões sexuais e, também, espaço de ressignificação da experiência humana de maneira extraordinária. A dama retorna, não mais para julgar somente pelo olhar, mas, também, para estabelecer um padrão de comunicação - a conversação intersexual - que faz com que o jogo da sedução se amplifique, obrigando o conquistador a adquirir atributos mais complexos do que beleza e força. Era preciso conquistá-la na lábia e somente o seu aval poderia legitimar uma relação no auge da cultura dos salões.

6) Contemporaneidade: a intensificação dos relacionamentos entre os sexos produz um aumento de interdição por parte da religiosidade cristã. Emerge o asceta vocacional e sua austera relação sexual, controlam-se com maior intensidade os desejos e a fuga para um relacionamento extraconjugal se torna a única maneira de experimentar um sentimento de salvação daquelas ordens de vida austeras criadas dentro do capitalismo moderno. A competição entre a religião e a sexualidade sublimada se acirram porque a primeira perdeu o monopólio de atribuição de significado para existência, tendo de concorrer com as esferas "irracionais" no campo da experiência salvífica.

É possível perceber que há uma direção clara do desenvolvimento da erótica e, também, uma intensificação contínua da tensão entre religiosidade e sexualidade sublimada. Existem duas forças antagônicas no desenvolvimento da própria erótica que se conjugaram em um determinado momento, mas que vivem em choque, são elas: a intelectualização do sexo e a experiência extracotidiana do amor. A figura da dama, nesse ponto específico, é fundamental, porque sintetiza tanto a possibilidade de experimentação extraordinária quanto o refinamento das relações sexuais (julgamento pelo olhar e conversação sexual). Grosso modo, tudo se resume a seguinte asserção:

A retirada do conjunto dos conteúdos da existência humana para fora do ciclo orgânico da existência camponesa e o crescente enriquecimento da vida com conteúdos culturais, fossem intelectuais ou de outros gêneros, dotados de valor supraindividual, ao separar o que era conteúdo da vida do que era meramente um dado da natureza, atuaram simultaneamente no sentido de reforçar a posição especial do erotismo. Ele foi alçado à esfera do gozo consciente (e gozo no sentido mais sublime da palavra). Não obstante isso e precisamente por causa disso, o erotismo, em contraste com os mecanismos de racionalização, deu-se a ver com uma porta que se abre para o cerne mais irracional e por isso mesmo o mais real da vida (WEBER, 2016, p. 388).

Podemos conectar aqui o pensamento de Norbert Elias sobre o desenvolvimento da erótica nos períodos analisado por ele no Processo Civilizador. Primeiro, é necessário dizer que a investigação de Elias trata o 
erotismo como um dos exemplos de sofisticação e refinamento das emoções do processo civilizador, sendo suas citações esparsas e muitas vezes pouco sistematizadas. O enfoque do seu argumento, quando se trata do sexo, é a passagem da idade média para o antigo regime e, por sua vez, deste para o período contemporâneo. Portanto ele inicia tratando exclusivamente da idade média e afirma:

Eram selvagens, cruéis, inclinados a explosões de violência e, de igual modo, abandonavam-se à alegria do momento. Podiam fazer isso. Pouco havia na situação em que viviam que os compelisse a adotar moderação em seus atos. Pouco em seu condicionamento os forçava a desenvolver o que poderíamos chamar de um superego rigoroso e estável, como função da dependência e das compulsões originárias de outras pessoas e que neles se transformassem em autodisciplina (ELIAS, 1993, p. 82).

O objetivo cognitivo está claro nessa passagem, trata-se de entender como se dera o processo de moderação dos instintos sexuais, qual era o papel que a homologia entre estrutura social e de personalidade causava em uma determinada figuração. Até o século XII havia um baixo grau de controle das pulsões e, por isso, "reinava a desconfiança em relação às mulheres, que eram basicamente objeto de satisfação sexual; o prazer na pilhagem e no estupro, o desejo de não reconhecer senhor algum" (ELIAS, 1993, p.83). Somente com a emergência da sociedade de corte é que haveria de se sublimar a experiência sexual, muito do porquê há, nesses espaços, uma intensificação da intelectualização das relações sociais. O serviço do homem à dama de corte, tão retratado pelo trovadorismo e pelo Minnesang ${ }^{1}$, é fruto único e exclusivo das emergentes sociedades de corte, praticamente inexistentes na maioria dos lugares e, por isso, exclusivamente elitista.

As grandes cortes absolutistas foram os lugares, na história europeia, em que se alcançou a mais completa igualdade até hoje conhecida entre as esferas de vida de homens e mulheres, e também, as de seu comportamento. Seria necessária uma digressão excessivamente longa para mostrar por que já as grandes cortes feudais do século XII, e as cortes absolutistas numa medida incomparavelmente maior, ofereceram às mulheres tantas oportunidades de superar a dominação masculina e de conseguir um status igual ao do homem. Observaram alguns autores, por exemplo, que no sul da França mulheres podiam, num estágio antigo, tornar-se senhoras feudais, possuir propriedades e desempenhar papel político (ELIAS, 1993, p. 90).

As damas se empoderam já no feudalismo, mas a forte ênfase no absolutismo nos faz ampliar a mirada genética de Weber. Em Elias há um

1 O Minnesang é um gênero literário de origem alemã e datado dentre os séculos XII e XIV tendo como principal figura a dama que deve ser cortejada pelo seu pretendente, um servo que muitas vezes não lhe era da mesma estirpe. O amor é o tema central dos poemas redigidos nesse estilo e entende-se que eram apresentados em sociedade cortesã. 
adicional, uma relação entre valorização sexual e estrutura de poder, as mulheres tornam-se senhoras feudais, condessas, rainhas e, por isso, ganham mais força para impor os seus desejos, principalmente para os seus súditos. Tal como Weber, a teoria de Elias advoga a tese de que a renuncia à violência física, à brutalidade ou à masculinizarão, tem a ver diretamente com o fortalecimento da importância social das mulheres. Interessante as afinidades que a obra de Elias também constrói com o pensamento sombartiano, pois para esse último, a sociedade de corte intensifica o destaque e a distinção social das amantes (1958, p.96) sendo que, por sua vez, elas são as reais inventoras da moda, do luxo e dos hábitos cortesãos: o exemplo de Madame Pompadour e seu estilo ${ }^{1}$ não nos deixa mentir, mas, também, não podemos esquecer do peculiar hábito do Rei $\mathrm{Sol}^{2}$ em construir solares e casarões para cada uma das suas maitresses.

As grandes cortes permitiam às mulheres - nobres, claro! - uma vida de luxo e de intelectualização, pois foram elas as que primeiro se dedicaram às leituras, contudo (pasmem!) a ênfase no erotismo é dedicada não ao relacionamento conjugal, mas ao extraconjugal, especificadamente, entre homens e mulheres de estamentos sociais diferentes (ELIAS, 1993, p.91; WEBER, 2016, p.390). Eis então que surge nosso protagonista:

[...] aquela transformação do prazer, aquela nuança de emoções, aquela sublimação e refinamento de sentimentos que chamamos "amor" finalmente surgiram. Não como exceção, mas em forma socialmente institucionalizada, surgiram contatos entre homem e mulher que tornaram impossível o homem forte simplesmente tomar a mulher quando ela lhe agradasse, o que tornava a mulher inacessível, ou acessível apenas a duras penas e, talvez porque fosse ela de classe mais alta e difícil de conquistar, especialmente desejável. Tal era a situação, o ambiente emocional da Minnesang, no qual, daí em diante, através dos séculos, os amantes reconheciam parte de seus próprios sentimentos (ELIAS, 1993, p. 92).

Aqui, mais uma afinidade, é a negação do acesso fácil e brutal ao sexo feminino que produziu esse refinamento e obrigou os homens a se curvarem, também, as vontades da dama. Então, tanto em Elias quanto em Weber, a intensificação dos desejos tem necessariamente que ver com uma renúncia, negação produzida como resultado do próprio desenvolvimento da estrutura

1 Até hoje persiste o estilo criado pela amante do rei Luis XV: cadeiras, camas, penteadeiras, toda a requintada mobília do lar pode ser considerada digna desse complemento à pompadour. O interessante da tese sombartiana (1958, p.122) reside em sua leitura do resultado da interiorização da sofisticação como mudança econômica e, também, desenvolvimento da própria subjetividade. Seria possível aqui conectar: Sombart, Elias e Sennett, sob os auspícios dessa ideia de desenvolvimento de uma subjetivação social que adentra os lares citadinos.

2 Luis XIV é reverenciado por suas extravagâncias, Sombart atribuiu a crise econômica subsequente ao estilo de gastança introduzida pelo Rei Sol. Foi ele, também, que revogando o Édito de Nantes, provocou o maior êxodo de huguenotes para outros países, inclusive, para a Prússia, fator considerado por Max Weber e outros economistas como fundamental para o desenvolvimento da manufatura alemã. 
social e de suas reverberações nas personalidades individuais. A sexualidade ${ }^{1}$ masculina é concebida aqui sempre como brutal, sendo que somente seu controle e o apaziguamento dos comportamentos é que poderiam levar a uma sofisticação - "femininização" - do sexo. São esses os resultados da transformação da paixão brutal em amor cortês. Cabe aqui, por último, uma pequena incursão na próxima "fase" do processo, entendendo o amor em tempos de civilidade:

A fim de ser realmente "cortês" segundo os padrões da civilité, o indivíduo é até certo ponto obrigado a observar, a olhar em volta e prestar atenção às pessoas e aos seus motivos. Nisto, também, anuncia-se uma nova relação entre um homem e outro, uma nova forma de integração (ELIAS, 1990, ps1702-1704).

Do ponto de vista da estrutura social, o processo civilizador é uma espécie de ampliação das diferentes relações sociais - figurações - estabelecidas entre os indivíduos, pois há um aumento progressivo na divisão de funções sociais e, também, nos laços de dependência, o que o faz Norbert Elias dialogar diretamente com a ideia de divisão do trabalho e de integração social. Do lado do indivíduo, ou melhor, da ação, poderíamos destacar que esse processo civilizador amplia a necessidade de levar em conta o outro, mesmo quando este "outro" não está presente, ou seja, a teoria weberiana da ação faria mais sentido depois do processo civilizador que antes; tal qual a teoria do superego de Freud, pois este só se desenvolveria plenamente com a auto coação das paixões praticada na corte e, no século XIX, ampliadas à exaustão pelo asceta protestante. Isso é interessante, pois mostra um caráter reflexivo na obra do autor que compreende a própria teoria social como resultado do contexto no qual é fabricada e nos permite pensar em como interpreta-lo(s) - Elias e Weber - como parte do processo social.

A civilidade é resultado e parte do aburguesamento do processo civilizador, constituída por uma transformação no tipo social que impõe o seu poder como classe dominante, já que é o padrão comportamental da classe dominante em um período que condiciona as possibilidades de desenvolvimento do processo (ELIAS, 1990, ps.3890-3892). Elias percebe que a intensificação do choque entre moral e sexualidade erigiu amplos diques de controle da "intimidade" de cada cidadão:

1 Richard Sennett (2015) tem uma ideia que me parece bastante interessante: a mudança conceitual que atribuiu a interpretação do sexual o epiteto de sexualidade, ao invés de erotismo, é, para o autor, uma mudança nas formas de concepção social do sexo. Isso porque, se o erotismo enfatizaria a ação, o ato de fazer sexo; a sexualidade coloca mais peso na identidade que um indivíduo possui a partir do atributo sexual. O que para Elias é fruto da intensificação do processo civilizador, para Sennett é uma transformação com mudança de direção - eu diria que para ele é até um retrocesso ou desvio negativo -, pois a subjetividade extremada produziria um narcisismo compulsivo e uma cultura que valoriza a autenticidade plena; quando, para o autor, eram aquelas formas anteriores de expressão e sociabilidade públicas que conduziram a sociedade ao que de melhor se produziu em termos de civilização. 
No processo civilizador, a sexualidade, também, é cada vez mais transferida para trás da cena da vida social e isolada em um enclave particular, a família nuclear. De maneira idêntica, as relações entre os sexos são segregadas, colocadas atrás de paredes da consciência. Uma aura de embaraço, a manifestação de um medo sociogenético, cerca essa esfera da vida. Mesmo entre adultos é referida apenas com cautela e circunlóquios. (ELIAS, 1990, p. 3663-3666).

"As grossas paredes do sigilo" erigidas entre os séculos XVIII e, principalmente XIX, fariam com que o aconselhamento educacional de um Erasmo de Roterdã ${ }^{1}$ parecesse indecente, pois, agora, as crianças são consideradas pequenos anjos que não poderiam saber mais nada da esfera do sexual. Uma enorme fissura foi constituída entre adultos e crianças no que tangia a sexualidade e vigorava desde então uma verdadeira omertà, o embaraço substituiu as formas anteriores de educação sexual e a família nuclear empoderada pelo próprio processo civilizador - passava a guardar a sete chaves os segredos, pois: "É proibida a simples menção de tais opiniões e instituições na vida social e referências a ela na presença de crianças são um crime que Ihes macula a alma ou, no mínimo, um erro muito grave de condicionamento" (ELIAS, 1990, os.3573-3577).

No próximo tópico trataremos - a título de conclusão - da última fase do processo de racionalização e, também, do processo civilizador no que concerne a sexualidade. Isso porque ambos terminam os seus desenvolvimentos com a emergência do ascetismo vocacional e sua moral sexual extremamente rigorosa que impôs aos indivíduos pesadas estruturas de contenção da sexualidade. Essa última fase nos servirá de gancho para tratarmos do período no qual viveram os dois personagens deste trabalho e no que podemos trazer de suas interpretações para pensar a erótica no século XXI.

\section{Considerações Finais ou sobre resultados imprevistos do desenvolvimento do amor em tempos do capitalismo}

O objetivo cognitivo do empreendimento de cada autor resulta em uma diferente percepção dos resultados que o aumento da relevância social do sexo produziu: enquanto para Weber existem desvios e regressões no processo de intensificação do erotismo tanto no período renascentista quanto da emergência do asceta vocacional na contemporaneidade; para Elias o aumento da repressão externa e interna do sexo é consequência do incremento de sua participação (do homem) na vida social. A ambiguidade constitutiva da erótica weberiana entre o potencial libertador do sexo, que só aparecesse com sua valorização como

1 Teólogo e filósofo tratado como referência maior do processo civilizador por ter redigido o texto "De civilitate morum puerilium". Para Elias, o seu texto marca definitivamente uma fase de passagem - ainda que seja pioneiro - nas transformações sociais que instituíram um novo conjunto de comportamentos considerados "civilizado", erigindo-se uma pacificação dos comportamentos sociais e, por sua vez, um aumento dos controles psicológicos e institucionais impostos aos indivíduos. 
esfera do extracotidiano, e o caráter racional da intelectualização do erótico, dialoga perfeitamente com a visão de Elias, pois para ele o desenvolvimento progressivo de códigos de comportamento, de regramentos e mesmo da reprovação como forma mais eficiente de punição na sociedade civilizada, impõem a estrutura de personalidade dos indivíduos novos padrões de conduta e comportamento, internalizados como naturais; assim, ao mesmo tempo que o sexo se parece com algo que foge dos comportamentos formais da sociedade civilizada também ele é regrado e determinado por uma série de pressões, que vão desde o embaraço ao tocar no assunto até sua total segregação para o âmbito privado e sigiloso - o quarto - da vida dos indivíduos.

A moral religiosa, que em Weber é o fator determinante de choque, em Elias aparece como elemento tópico, expressão em uma instituição de um regramento que lhe é superior porque posto em toda a estrutura social por meio do seu conjunto de repressões externas e, muito mais, pela consolidação das repressões internas que constituem o violento superego da sociedade civilizada. No interessante estudo sobre os alemães, Elias (1997) demonstra como o alto grau de formalismo da cultura alemã represava emoções violentas em uma estrutura de personalidade extremamente autoritária, servindo como diques de contenção que foram destruídos pelo movimento de massas do nazismo. Convém retornar à citação de Weber para ficar mais clara a distinção entre as interpretações dos autores:

O último estágio de acentuação valorativa pelo qual passou a esfera erótica consumou-se finalmente no terreno das culturas intelectualistas, justamente ali onde a esfera erótica bateu de frente com o influxo inevitavelmente ascético do tipo de homem profissional por vocação [Berufsmenschentum]. Em meio a essa relação de tensão com o cotidiano racional, a vida sexual tornada extracotidiana e especialmente extramatrimonial pôde aparecer como o único vínculo que ainda ligava à fonte natural de toda vida o ser humano ora em diante completamente solto do ciclo da antiga existência camponesa, simples e orgânica (WEBER, 2016, p.390391).

Ocorre que a última fase da erótica está dada na emergência do asceta vocacional como principal personagem daquele período, sendo a naturalização racional da sexualidade a principal forma de expressão do puritanismo na esfera erótica. O relacionamento extraconjugal passa a ser a única forma possível de escapar da intelectualização moralizadora do sexo, pois com as amantes e até com as prostitutas ${ }^{1}$ era possível fugir as pressões sociais que condenavam o casal ao sexo apenas para procriação. O matrimônio ganha destaque

1 A sociedade alemã do entre séculos vivia o problema da prostituição, que segundo Simmel, era resultado do modelo de formação da elite intelectual, política e econômica alemã. O elevado tempo em que os jovens viviam às custas dos pais e a negação deliberada do casamento antes da emancipação financeira fazia com que os jovens canalizassem os seus desejos sexuais diretamente para os prostíbulos, condenando pobres jovens a prostituição e ao mal das doenças venéreas. Ver: SIMMEL, Georg. Algumas "Reflexões sobre a Prostituição no Presente e no Futuro" in: SIMMEL, Georg. Filosofia do amor. 3. ed. São Paulo, SP: Martins Fontes, 2006. 
novamente, mas a mulher não passa a ser mais valorizada como pareceria à primeira vista, pois:

A opinião social condena agora (no século XIX) todas as relações extramatrimoniais entre os sexos, embora nesta esfera, ao contrário da sociedade de corte, o poder social do marido volte a ser maior que o da esposa, de modo que a violação do tabu pelo marido geralmente é julgada com mais condescendência do que a mesma falta cometida pelas mulheres. Mas ambas as quebras de padrão têm, nessa época, de ser inteiramente excluídas da vida social oficial. Ao contrário do que acontece na corte, devem ser rigorosamente confinadas atrás da cena, banidas para o reino do segredo (ELIAS, 1990, ps.3774-3778).

No período da civilidade, o empoderamento feminino é menor que o da sociedade de corte, o luxuoso ${ }^{1}$ relacionamento erótico das elites é substituído por um modo de condução da vida eminentemente burguês e puritano, porque foram aqueles prêmios psicológicos que o puritanismo ofereceu ao burguês que Ihe fizeram prosperar para além da classe antecessora que lhe cedera os anéis. A humilhação (BERICAT ALASTUEY, 2001) produzida pela angustiante incerteza quanto à possibilidade de salvação - doutrina da predestinação - fortaleceu o senso de comprovação entre as seitas protestantes, que acabou sendo utilizado tanto nos negócios do céu quanto naqueles da terra, tendo em vista que "o bom pagador é dono da bolsa alheia", ou seja, que aquele que é reconhecido como honesto, trabalhador, que comprova sua fé no comprometimento do seu trabalho é recompensado com a confiança da comunidade de Deus. $E$ é exatamente por isso que:

Do ponto de vista de qualquer ética religiosa da fraternidade, quanto mais sublimada for a relação erótica, tanto mais ela deverá permanecer presa à brutalidade, e isso de um modo particularmente refinado. Aos olhos dessa ética, a relação erótica aparece, inevitavelmente, como uma relação de luta, não só nem principalmente por causa do ciúme, da vontade de possuir alguém com exclusão de terceiros, mas muito mais, e mais intimamente, porque jamais os próprios parceiros a percebem como tal, a saber: como uma violação da alma do companheiro menos brutal, como um refinado - pois aí se trata da mais humana das entregas de si - um dissimulado gozo de si no outro (WEBER, 2016, p.392-393).

Para a religião, mas também para a terapia, a relação erótica tomada como um fim em si mesmo no fundo é uma forma egoísta de explorar o prazer para si

1Para incursões futuras, uma comparação entre o amor como luxo de Werner Sombart e o processo civilizador de Elias seria muito interessante, pois o requinte dos costumes a mesa, do bem alimentar-se, das relações sexuais com cortesãs, todas essas características que Elias atribuiria ao processo civilizador; para Sombart, são expressões acabadas do capitalismo no campo do consumo, dado que os mercados mundiais abasteciam os consumidores citadinos das cortes. 
através do corpo do outro. Nesse caso a libertação prometida pelo erotismo é uma dominação mais sofisticada, tal qual a liberdade da mulher - e também dos homens - na sociedade de corte, pois:

A mulher era mais livre de restrições externas do que na sociedade feudal. Mas a coação interior que ela era obrigada a impor a si mesma de acordo com a forma de integração e com o código de comportamento em vigor na sociedade de corte, que se originavam ambos dos mesmos aspectos estruturais dessa sociedade que engendraram sua "liberação", havia aumentado para ela e para os homens em confronto com a sociedade cavalheirosa (ELIAS, 1990, p. 3761-3764).

Por isso, mesmo quando falam de coisas diferentes em momento históricos diferentes, Weber e Elias conseguem capturar a ambiguidade daquela visão progressistas que o positivismo ingênuo carregara para a sociologia. Novas formas expressão da liberdade eram acompanhadas por novos modelos de dominação, o que outrora poderia ser considerado como uma emancipação, agora, recebia um conjunto de determinações que impediam qualquer libertação real. Pois então, qual seria o destino do erotismo no século XX?

Em suma, nessa área de risco da vida social humana - a sexualidade - os padrões de controle social, a prática social e a consciência pessoal mudaram consideravelmente em conjunto durante 0 século $X X$. Uma estratégia de encobrimento e recalcamento, particularmente na relação entre grupos de certa posição social e poder e as gerações emergentes, estratégia que parecia àqueles comprometidos com ela auto evidente e necessária para a sobrevivência da sociedade humana, isto é, como moral per se, mostrou-se na prática um elo funcional dentro de uma sociedade fundada sobre estruturas de poder específicas. Quando essas estruturas foram substituídas por uma distribuição de poder menos desigual - entre dominadores e dominados, entre os sexos e as gerações - , também mudou a estratégia de repressão. A ordem não cedeu ao caos quando o alto patamar vitoriano de vergonha e embaraço em torno da vida sexual se reduziu, e o segredo formalizado deu lugar a um comportamento e um discurso mais abertos (ELIAS, 2001b, p. 11).

Datado de 1982, o texto que deu origem ao livro A Solidão dos Moribundos agrega em alguns exemplos no campo do amor e sexualidade que Elias usa para comparar como procedeu o desenvolvimento de certos padrões de comportamento para com os adoecidos e velhos. Nesse pequeno parágrafo condensa-se um diagnóstico posterior aquele que o autor havia desenvolvido sobre a sexualidade no processo civilizador, muito do porquê nesse interregno de tempo transformações profundas abalaram as noções tipicamente vitorianas de civilidade no campo do erotismo. Uma grande revolução sexual já havia se espraiado por todo o globo e o ordenamento foi reorientado em suas formas de controle da vida sexual. 
A tensão inabalável do período erótico, seus modelos de castração dos sentimentos e as sigilosas "escapadas" como forma de experimentação do extraordinário se tornaram tão obtusas quanto as vestimentas formais ou até mesmo os cortes de cabelo em coque e as perucas dos séculos XVIII. Creio que Elias e Weber já viviam, nos idos das décadas dez e vinte, as últimas lamentações da sexualidade vitoriana, que sofreria um grande impacto com a revolução sexual dos anos precedentes. De certa forma, a emergência dos movimentos eróticos no início do século XX e a própria circulação de um discurso sobre o sexo já apontavam uma mudança, pois o que seria do sigilo ou embaraço depois da descoberta do inconsciente e da teoria da libido freudiana? O que seria da educação sexual, após a descoberta da sexualidade infantil? O que seria, por fim, da moralização religiosa da cópula, após o descobrimento dos métodos contraceptivos?

Creio que podemos tratar o diagnóstico de ambos os autores como documento históricos, como Elias quando recupera Erasmo de Roterdã para entender nos seus escritos o pioneirismo de uma transformação social profunda. O contexto social ${ }^{1}$ de emergência da sexualidade como um assunto a ser tratado - por Freud, Gross, Weber, Simmel, Sombart, Elias e tantos outros - só demonstra que, de alguma forma, o processo civilizador ou a racionalização da sexualidade estavam em vias de se transformar e, talvez, esses pensadores foram aqueles precursores que se puseram a refletir sobre aquilo que se desenvolveria ainda mais no decorrer das décadas.

\section{REFERÊNCIAS}

BERICAT ALASTUEY, E. Max Weber o el enigma emocional del origen del capitalismo. Reis: Revista Española de Investigaciones Sociológicas, 95, 936.2001.

ELIAS, Norbert. Norbert Elias por ele Mesmo. Tradução de André Telles. Rio de Janeiro: Jorge Zahar, 2001.a.

ELIAS, Nobert. A sociedade de corte: investigação sobre a sociologia da realeza e da aristocracia de corte. Rio de Janeiro: Zahar, 2001.c. E-BOOK.

ELIAS, Nobert. A solidão dos moribundos. Rio de Janeiro: Zahar, 2001.b. EBOOK.

ELIAS, Norbert. Introdução à sociologia. Tradução de Maria Luísa Ribeiro Ferreira. Lisboa: Edições 70, 2008.

ELIAS, Nobert. O processo civilizador 1: uma história dos costumes. Rio de Janeiro: Zahar, 1990. E-BOOK.

1 Talvez, em um trabalho posterior, venha a discutir essa determinação social do pensamento dos dois autores de maneira mais extensiva e à luz de suas teorias sociológicas. 
ELIAS, Nobert. O processo civilizador 2: formação do estado e civilização. Rio de Janeiro: Zahar, 1993. E-BOOK.

Fragmentado. Direção de M. Night Shyamalan. EUA: Universal Pictures. 2017.

HONIGSHEIN, Paul. On Max Weber. New York, NY: Free, 2017. Ebook Kindle.

JAMESON, Fredric. "The Vanishing Mediator: Narrative Structure in Max

Weber" New German Critique, n. 1, 1973, p. 52-89. JSTOR, www.jstor.org/stable/487630 Accesso em: 20 jan. 2021.

LANDINI, Tatiana Savoia. "Horror, honra e direitos. Violência sexual contra crianças e adolescentes no século XX. 2005. Tese (Doutorado em Sociologia) - Faculdade de Filosofia, Letras e Ciências Humanas, Universidade de São Paulo, São Paulo.

MONTIEL, Francisco Gil-Villegas. Max Weber y la guerra académica de los cien años: história de las ciencias sociales en el siglo XX. México: Fondo de la Cultura Económica, 2015. E-BOOK.

PEDRON, C. C. Salvação intramundana pela perversão? Sobre a possibilidade emancipatória através da esfera erótica de Max Weber in: QUERIDO, F.M. (et al.). Teorias Críticas entre passado e presente, Coleção Ideias; IFCH, 2019.a.

PREVIATTI, Débora. Weber em Elias em "A sociedade de corte" e "O processo civilizador". 2016. Trabalho de Conclusão de Curso (Graduação em Ciências Sociais) - Universidade Federal de Florianópolis, Santa Catarina.

SENNETT, Richard. O declínio do homem público: As tiranias da intimidade. Record,2015 (e-book).

SIMMEL, Georg. Algumas "Reflexões sobre a Prostituição no Presente e no Futuro" in: SIMMEL, Georg. Filosofia do amor. 3. ed. São Paulo, SP: Martins Fontes, 2006.

SCHLUCHTER, Wolfgang. Acción, orden y cultura: Estudios para um programa de investigación em conexión con Max Weber. Buenos Aires: Prometeo Libros, 2008.

SCHLUCHTER, Wolfgang. Paradoxos da modernidade: cultura e conduta na teoria de Max Weber. São Paulo, SP: Editora UNESP, 2011.

SOMBART, WERNER. Lujo y Capitalismo. Tradução de J.A. Garcia Martinez. Guilherme Dávalos Editor, 1958. 
TENBRUCK, Friedrich H., and Max Weber. "The Problem of Thematic Unity in the Works of Max Weber." The British Journal of Sociology, v. 31, n. 3, 1980, p. 316-351. Disponível em: www.jstor.org/stable/589370 Acesso em: 18 abr. 2019.

WEBER, Marianne, and E. S. "ACADEMIC CONVIVIALITY" Minerva, v. 15, n. 2, 1977, p. 214-246, 1977.

WEBER, Marianne. Excerpt from "Authority and Autonomy in Marriage. In: Lengermann, Patricia Madoo; Niebrugge, Gillian. The Women Founders:

Sociology and Social Theory 1830-1930. New York: Waveland Press.1998. Edição do Kindle.

WEBER, Max. Ética Econômica das Religiões Mundiais: Ensaios comparados de sociologia da religião. Vozes, 2016.

Recebido em: 19 de fevereiro de 2021. Aceito em: 15 de junho de 2021. Publicado em: 30 de junho de 2021. 